\title{
Ototoxicidad por medicamentos
}

\section{Drug-induced ototoxicity}

\author{
Víctor Mercado M¹, Rodolfo Burgos S², Claudio Muñoz V³.
}

\begin{abstract}
RESUMEN
Se define ototoxicidad a las perturbaciones transitorias o definitivas de la función auditiva, vestibular, o de las dos a la vez, inducidas por sustancias de uso terapéutico'.

Son muchos los trabajos de investigación que se han dedicado ha este tema quedando aun dudas por resolver debido a las complejas consecuencias donde está envuelto el daño cocleovestibular. El propósito de esta revisión, es presentar las últimas teorías que tratan de explicar desde el punto de vista de la farmacocinética/farmacodinamia, biología celular y molecular el mecanismo por el cual actúan los fármacos involucrados. Lo anteriormente señalado tiene como fin que los últimos adelantos en esta materia, permitan una mejor comprensión que nos lleve a una práctica clínica más segura con relación a la ototoxicidad medicamentosa, dando a conocer los cuidados y precauciones que se deben tomar antes de administrar un fármaco que se reconoce ototóxico, que puede tener graves consecuencias en la calidad de vida de nuestros pacientes.
\end{abstract}

Palabras clave: Ototoxicidad, toxicidad vestibular, toxicidad coclear, medicamentos ototóxicos.

\section{FALTA ABSTRACT}

Ototoxicity is defined as the transient or definitive perturbations of the auditory and/ or vestibular function, induced by drugs of therapeutic use.

Despite a large body of literature devoted to this subject, there are still unanswered questions, due to the complex consequences of cochleovestibular damage. The present study aims to review recent theories that try to explain the mechanism of action of involved drugs, from the viewpoint of pharmacokinetics/ pharmacodynamics, cell and molecular biology. Our purpose is that recent advances in this matter could lead to a better understanding and safer clinical practice related to drug-induced ototoxicity, summarizing the care and precautions that should be taken when administering a known ototoxic drug.

Key words. Ototoxicity, vestibular toxicity, cochlear toxicity, ototoxic drugs.

\footnotetext{
Médico Otorrinolaringólogo, Sanatorio Marítimo San Juan de Dios, Viña del Mar.

2 Médico General, Hospital de San Carlos, San Carlos.

3 Médico General, Centro de Salud Dr. Eduardo Raggio, Catemu.
} 


\section{INTRODUCCIÓN}

Estamos viviendo en una época donde el mercado farmacéutico día a día nos presenta nuevas opciones terapéuticas que se presentan con múltiples ventajas sobre sus antecesores. Sin embargo, esto no ocurre con los aminoglucósidos, fármacos que nos acompañan desde 1944 (estreptomicina) y se han mantenido con vigencia en la práctica clínica pero que aún hay mucho que necesitamos saber de ellos debido a que están asociados a graves complicaciones que necesitamos reconocer en forma oportuna. El propósito de esta revisión es presentarles una puesta al día, no sólo para el médico especialista sino también para aquel que hace medicina general donde el uso de aminoglucócidos es frecuente, poniendo énfasis en su potencial daño cocleovestibular. Introduciremos el tema con un caso clínico que muestra que en medicina no basta con hacer el diagnóstico, sino también un buen esquema terapéutico que cure una enfermedad sin dejar secuelas iatrogénicas que deterioran la calidad de vida de una persona y que en algunos casos podrían llegar a ser permanentes como ocurrió con el caso clínico que a continuación detallaremos.

\section{CASO CLÍNICO}

Anamnésis: Paciente de sexo femenino, de 86 años de edad, con antecedentes de gastrectomía total siete años antes. Sin otra patología asociada, con 42 kilos de peso, manteniendo controles anuales y en buenas condiciones generales. Durante el verano de 2004 sufre malestar vías urinarias por lo que consultó médico quien diagnosticó infección del tracto urinario (ITU).

- Resultado de exámenes: Agente microbiano sensible a gentamicina.

- Tratamiento indicado: Gentamicina 160 mg/día por 7 días, por vía intramuscular.

- Evolución: al día siguiente de completado el esquema antibiótico, comenzó con mareo permanente, pérdida importante de equilibrio en la bipedestación que cedían en posición decúbito. Se le indica Examen Funcional de VIII Par Craneal.
Resultado Examen VIII Par con ENG:

- Acumetría: Pruebas de diapasones normales

- Audiograma:

- Oído izquierdo (OI): Hipoacusia sensorioneural con buena discriminación, promedio tonal puro (PPT) $23,3 \mathrm{~dB} \mathrm{HL}$

- Oído derecho (OD): Hipoacusia mixta con buena discriminación, PPT 36,6 dB HL, diferencia ósteo-aérea pequeña.

- Equilibrio: Romberg y Romberg sensibilizado

(-) presentando retropulsiones

- Marchas: 0jos abiertos: inestable e insegura

- Ojos cerrados: inestable, desvía a izquierda

- Sobre una línea: lateropulsiones bilaterales mayores a izquierda.

- Prueba de brazos extendidos: No desvía

- Indicaciones: No desvía

- Cerebelo: Sin signología cerebelosas

- Nistagmo Posicional: No presenta

- Seguimiento pendular: tipo II

- Movimientos sacádicos: leve alteración en velocidad y exactitud

- Nistagmo Optokinético: Disminución de la velocidad componente lento (VCL) bilateral en respuesta a estímulos a $40 \% \mathrm{seg}$

- Nistagmo Espontáneo: No presenta ni con ojos cerrados ni abiertos.

- Prueba Calórica según VCL:

- Hipoexcitabilidad Vestibular Bilateral mayor OI $33 \%$

- Dirección preponderante a Izquierda 11\%.

- Observaciones: En todas las pruebas poscalóricas se observan sacudidas nistágmicas.

- Se irriga a $17^{\circ} \mathrm{C}$ en ambos oídos.

Examen clínico actual: Paciente con gran incapacidad para la marcha e importante limitación para sus actividades diarias.

\section{FÁRMACOS}

Se descrito en la literatura una larga lista de fármacos ${ }^{2}$ a los que se atribuye como reacción adversa algún grado de ototoxicidad, de los cuales se revisarán en extenso las familias de fármacos que presentan mayor asociación, como son los antibióticos aminoglucósidos y diuréticos de asa. 
Tabla 1: farmacos causantes de ototoxicidad

\begin{tabular}{|ll}
\hline Antibióticos aminoglucósidos & Dihidroesptreptomicina \\
& Gentamicina \\
& Neomicina \\
& Tobramicina \\
& Amikacina \\
& Netilmicina \\
& Polimixina B \\
& Polimixina E (Colistina) \\
Diuréticos & Furosemida \\
& Ácido Etacrínico \\
& Bumetanida \\
AINES & Piretanida \\
& Torasemida \\
& Indometacina \\
& Naproxeno \\
Aerivados de la quina (antimaláricos) & Fenoprofeno \\
& Ácido Mefenámico \\
& Piroxicam \\
Antineoplásicos & Quinina \\
& Cloroquina \\
& Pirimetamina \\
& Cisplatino \\
& Mostaza Nitrogenada \\
& Bleomicina \\
& Carboplatino \\
& Dactinomicina \\
& Droloxifeno \\
& Vincristina \\
& Misonidazol \\
& Ciclofosfamida \\
& Ifosfamida \\
& Metotrexato \\
& \\
&
\end{tabular}

Fuente: V. Palomar García, F. Abdulghani, E. Bodet, L. Andreu Mencía, V. Palomar Asenjo. Otoxicidad producida por medicamentos: Estado actual, ORL-DIPS 2001; 28 (1):7-11.

\section{ANTIBIÓTICOS AMINOGLUCÓSIDOS (AAG)}

Esta familia merece ser mencionada en primer lugar no tan solo por su importancia histórica sino también clínica.

Los aminoglucósidos pueden causar ototoxicidad que, en ocasiones, es irreversible. Las alteraciones auditivas son consecuencia de la destrucción de las células sensoriales del oído interno, ya sea a nivel de la cóclea o de los órganos vestibulares.

En la actualidad, aunque pueden utilizarse en monoterapia, se utilizan fundamentalmente en combinación con betalactámicos en infecciones graves. Los conocimientos sobre los parámetros farmacocinéticos y farmacodinámicos han sugerido su uso en monodosis, cuya eficacia ha sido similar a la administración en multidosis además de presentar menor toxicidad ${ }^{3}$. Los efectos adversos más comunes son la nefrotoxicidad y la ototoxicidad, de las cuales es esta última la que menos importancia se le presta, principalmente por desconocimiento.

Fue la tuberculosis la que originó, al final de la Segunda Guerra Mundial, en 1944, el uso de la estreptomicina ${ }^{1,4}$. Ésta en un comienzo se usó en 
altas dosis en los pacientes con tuberculosis, que si bien conseguían sobrevivir presentaban oscilopsias y vértigos rotatorios ${ }^{1,5}$. Posteriormente aparecieron el resto de integrantes de esta familia, todos ellos con un grupo amino, lo que les confiere su carácter básico, responsable de su actividad ante bacterias gram negativas, pero también de sus efectos tóxicos sobre oído interno y riñón ${ }^{1,6}$.

Su estructura química se compone de aminoazúcares unidos por enlaces glucosídicos a un alcohol cíclico hexagonal con grupos amino (aminociclitol) ${ }^{3}$. Su estructura no es susceptible de modificación sin perder su actividad antimicrobiana.

Se ha visto que los diferentes AAG presentan cierto grado de toxicidad coclear $y / 0$ vestibular dependiendo del AAG.

Los aminoglucósidos no se absorben por el tracto gastrointestinal, de manera que hay que administrarlos por vía intramuscular 0 endovenosa. Se distribuyen libremente en el espacio vascular y de forma relativamente libre en el líquido intersticial de la mayoría de los tejidos, debido a su escasa unión a proteínas y alto nivel de solubilidad. Atraviesan escasamente las membranas biológicas con la excepción de las células tubulares renales y las del oído interno, que muestran una cinética de captación de aminoglucósidos saturable ${ }^{3}$. La administración en aerosol consigue en la secreción bronquial mayor concentración que la administración parenteral, con menos ototoxicidad y nefrotoxicidad?

Todos los aminoglucósidos son excretados por filtración glomerular sin alteración metabólica previa.

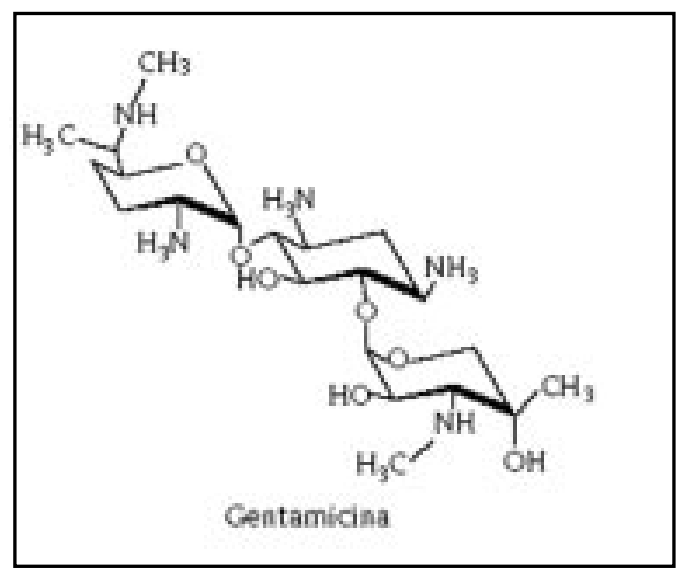

Figura 1.
Los aminoglucósidos muestran un patrón de actividad bactericida que es dependiente de la concentración alcanzada y no del tiempo de exposición. Por tanto, el objetivo del tratamiento con aminoglucósidos es dar la dosis más alta posible para actividad bactericida, bordeando el límite inferior de toxicidad ${ }^{3,8}$.

La acción de los aminoglucósidos comprende una interacción inicial con la superficie externa de la membrana celular bacteriana, transporte a través de la membrana interna y, finalmente, la unión a la subunidad $30 \mathrm{~S}$ de los ribosomas bacterianos, que inhibe la síntesis de proteínas, conduciendo finalmente a la muerte del microorganismo.

Los aminoglucósidos se administraron clásicamente mediante la pauta de multidosis a pacientes con función renal normal, sin embargo, diversos estudios han ido demostrando en las dos últimas décadas que también es eficaz la pauta de monodosis, que utiliza intervalos de 24 horas viéndose que monodosis era igual de eficaz y tendería a ser menos nefrotóxica que la pauta de multidosis.

\section{ESTUDIO MORFOLÓGICO}

\section{Generalidades}

El uso de microscopía óptica con contraste de fase, mostró de manera más precisa la localización de las lesiones laberínticas:

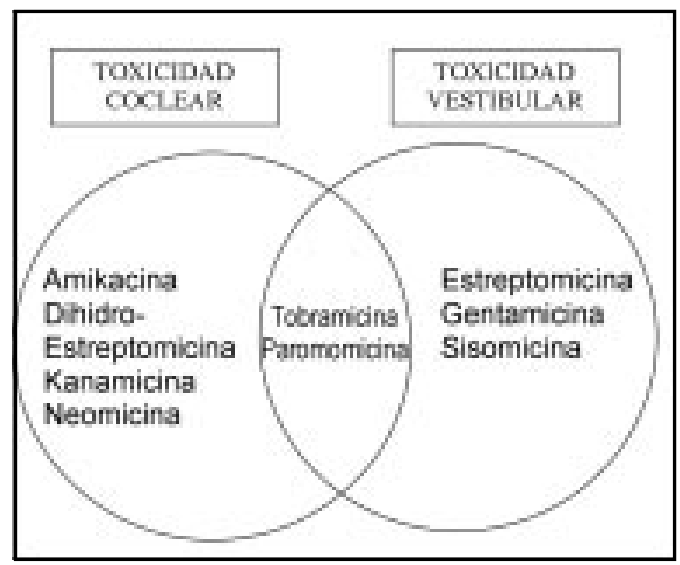

Figura 2. 
- Destrucción selectiva de las células sensoriales, en órgano de Corti, esencialmente de las células ciliares externas (CCE), cuya función es ya reconocida? .

- En órganos vestibulares (células de la mácula sacular en el caso de la gentamicina).

Al mismo tiempo la microscopía electrónica de transmisión, complementó lo anteriormente señalado con los cambios en la ultraestructura de las células sensoriales secundarias al uso de aminoglucósidos ${ }^{1}$. Los AAG no lesionan directamente el octavo par $^{10}$.

\section{Descripción de las lesiones}

La ototoxicidad de los AAG es provocada primariamente por una destrucción selectiva de las células sensoriales del oído interno, ya sea a nivel de la cóclea o de los órganos vestibulares. Solo algunos autores reconocen este efecto como secundario a alguna alteración en otras estructuras como la estría vascular'.

En el modelo de toxicidad coclear, la distribución de las lesiones en el órgano de Corti depende del tipo de AAG, dosis diaria y tiempo de uso.

No obstante lo más frecuente es que la destrucción afecte a las CCE. Dentro de las CCE la primera hilera en afectarse es la interna, luego la del medio y finalmente la externa. Se ha observado que puede haber una reducción en $70 \%$ de las CCE sin alteraciones electrofisiológica, las que aparecen si se afecta el $30 \%$ restante. Este modelo de sordera es distinto a otros como el por ruido, donde el daño se produce en la hilera interna de las CCE y en las células ciliares internas (CCI)1.

El segundo rasgo característico es su localización limitada al principio de la base de la cóclea y en caso de mantenerse la noxa su extensión progresiva al ápex. Esta presentación topográfica tiene importancia del punto de vista clínico el cual se tratará más adelante.

En el análisis morfológico de los cilios sensoriales aparece precozmente una aglutinación de los cilios seguida de una fusión de los mismos, debido a una rarefacción del glucocáliz, que normalmente recubre su superficie y mantiene así una distancia entre ellos. Esta alteración no es específica de ototoxicidad pero su ubicación es particularmente similar a la distribución de la destrucción de las células ciliares.
También se observaron cambios de ultraestructura:

- Modificaciones mitocondriales a nivel de las crestas ampollares.

- Acumulación de lisosomas secundarios en el polo superior de las CCE.

El significado de estas lesiones todavía no ha sido dilucidado.

\section{PATOGENIA}

No se conoce con exactitud, existiendo diferentes teorías explicativas, resumiéndose estas en la Figura 4.

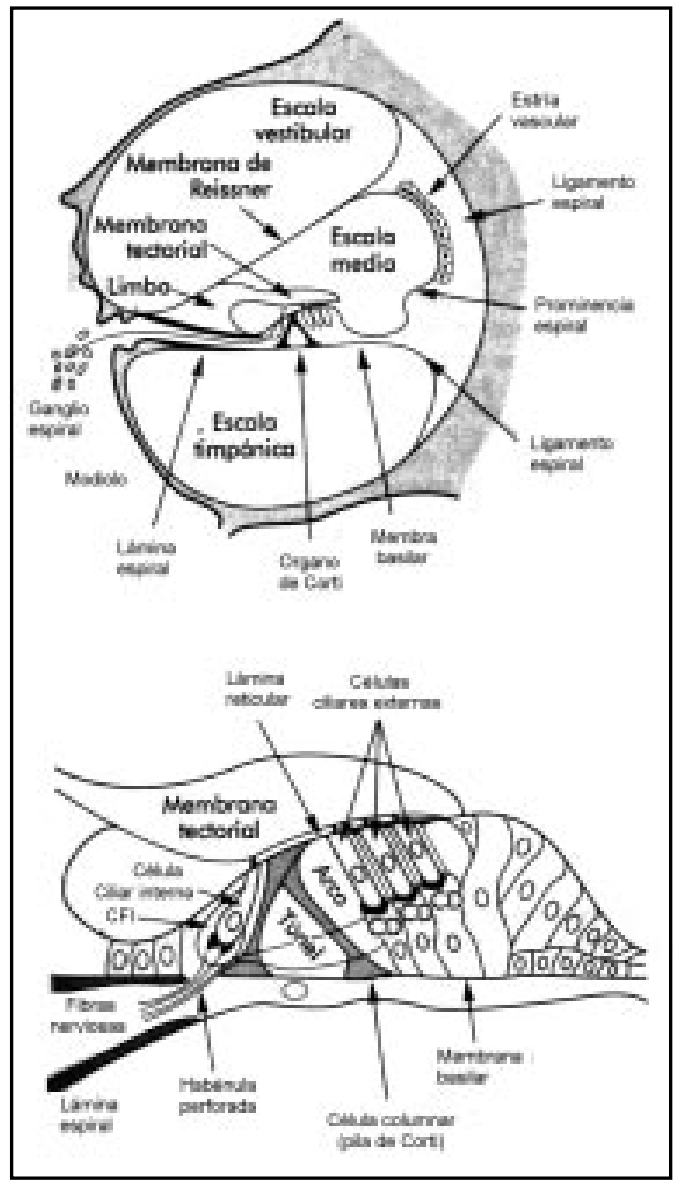

Figura 3. 


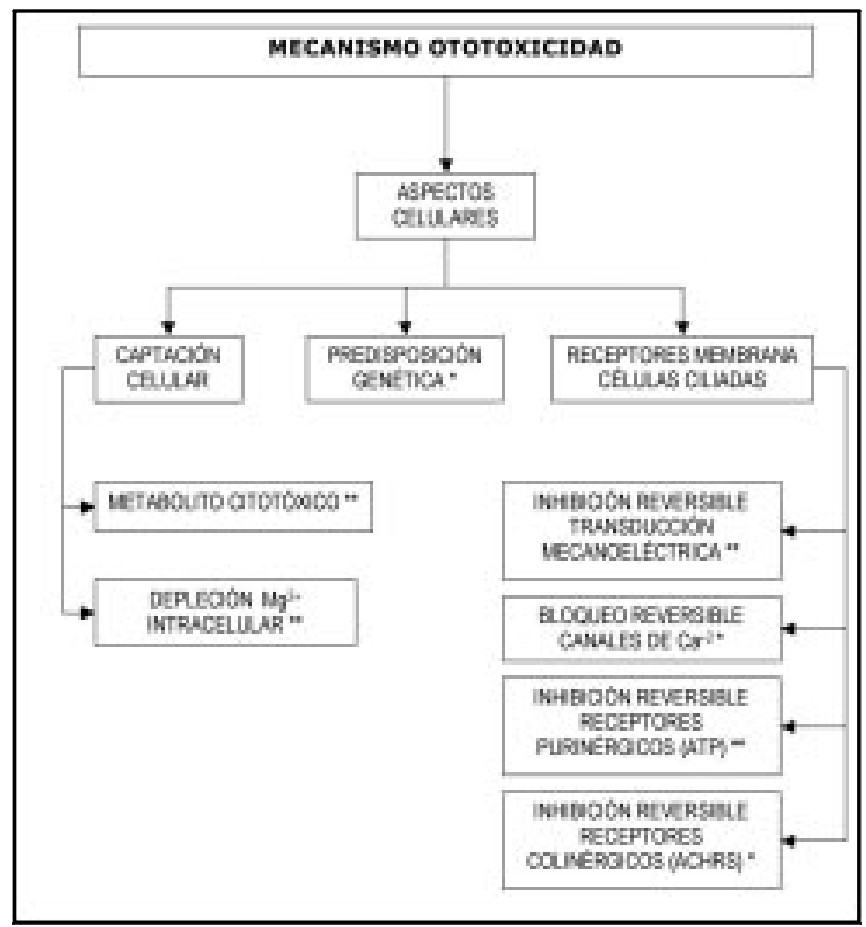

Figura 4.

\section{Aspectos celulares y moleculares de la acción tóxica de los AAG}

1. Efectos extracelulares sobre diferentes receptores de membrana de las células ciliadas. A pesar de su pequeño tamaño los AAG atraviesan muy mal las membranas biológicas por simple difusión debido a sus propiedades de base policatiónica. La penetración intracelular es por transporte activo como endocitosis. Debido a su naturaleza policatiónica estas moléculas son fuertemente atraídas por receptores de membrana con carga opuesta.

A. Inhibición reversible de la transducción mecanoeléctrica

El canal de transducción mecanoeléctrico situado en el apex de cada estereocilio se considera un poro poco permeable poco específico que permite el paso de diferentes cationes, por ejemplo, $\mathrm{K}+, \mathrm{Na}+\mathrm{O} \mathrm{Ca}$. El desplazamiento de cada cilio durante el estímulo mecánico modificará en un sentido excitador o inhibidor la probabilidad de abertura de estos canales de transducción. Los AAG actuarían bloqueando la boca del canal de manera reversible. Esto adquiere más importancia si se considera que la célula está hiperpolarizada lo que indica que el campo eléctrico de la membrana atrae las moléculas cargadas a la boca del canal.

B. Bloqueo reversible de los canales de $\mathrm{Ca}^{+2}$

Los AAG también han sido presentados como los inhibidores potenciales de los canales de calcio de la membrana plasmática de las células ciliadas cocleares. Este efecto es el responsable del efecto neuromuscular paralizante de algunos de estos antibióticos, ya que estos canales son responsables a nivel presináptico de la secreción de acetilcolina.

C. Inhibición reversible de los receptores purinérgicos (ATP)

Las células ciliadas poseen receptores de membrana para el ATP extracelular llamados receptores purinérgicos. El ATP va a actuar como neuromodulador/neurotransmisor que va a influir en la homeostasis y modificar las propiedades eléctricas de las células sensoriales. Los AAG inhiben en forma reversible las 
corrientes eléctricas, en forma similar a los canales de transducción mecanoeléctrica.

D. Inhibición reversible de los receptores colinérgicos (AChRs)

Las CCE de la cóclea son inervadas por el sistema eferente colinérgico. La activación de este sistema tiene un efecto inhibidor sobre la función coclear, a través de receptores nicotínicos. Esta acción puede ser rápida y reversiblemente eliminada por una inyección única de gentamicina.

2. Captación celular. Los efectos inhibidores descritos en los párrafos sobre los diferentes receptores de membrana no justifica por si solos la destrucción selectiva de las células ciliares ni CCE en particular.

Estudios de farmacocinética a nivel celular demuestran la captura de AAG preferente por las CCE. La acción tóxica irreversible de esta molécula parece pues ser intracelular. Además se ha propuesto la formación de un metabolito citotóxico resultante de la transformación de esta molécula. Los AAG se acumulan a nivel celular en las estructuras lisosomales y se ha observado que su eliminación es un proceso lento.

Se ha postulado que los AAG aumentarían la permeabilidad de la membrana celular al $\mathrm{Mg}^{2+}$, 10 conduciría a una depleción intracelular de este ion, lo cual detendría una serie de reacciones bioquímicas, especialmente la fosforilación oxidativa en la cual el $\mathrm{Mg}^{2+}$ es un cofactor y la célula perderia su funcionalidad e integridad ${ }^{10}$.

Pese a todo lo anterior aún no está totalmente clarificado el mecanismo exacto de daño celular que lleva a la destrucción final de la célula.

3. Teorías genéticas. A nivel de células ciliadas cocleares dos genes mitocondriales, el tRNA y el 12S rRNA, han sido asociados con disminución acústica no sindromática. La mutación en el gen 7445G (substitución de guanina por adenosina) en el gen tRNA serina, puede causar disminución de la audición.

El segundo gen mitocondrial implicado en una disminución de la audición es el ribosoma pequeño (12s rRNA). La mutación del gen A1555G provoca en los pacientes una disminución de la audición debido a ototoxicidad por aminoglucósidos. Esta mutación probablemente hace que la estructura de
rRNA de la mitocondria humana sea más similar al rRNA bacteriano que es el blanco de la acción de los aminoglucósidos, generando mayor concentración y por lo tanto mayor daño en células susceptibles. Una segunda mutación patogénica, la delección de una timina en posición 961 (961 del $\mathrm{T})$, ha sido recientemente manifestado que predispone a los pacientes a toxicidad por aminoglucósidos y disminución de la audición ${ }^{11}$.

La ototoxicidad farmacológica es una importante causa de disminución acústica. En los EE.UU, 10\% de las personas portadoras de sordera presentan la mutación mitocondrial 12s ribosomal (rRNA), incluyendo la sustitución A 1555 G que está asociada a una extrema sensibilidad por AAG. Un caso en 20.000 a 40.000 nacidos se estima la prevalencia del gen $A$ $1555 \mathrm{G}$ como causa de sordera en los EE.UU ${ }^{12}$.

Al descubrir estos antecedentes se realizó un estudio de prevalencia de la mutación de este gen A $1555 G$ en el ADN mitocondrial en una población española cuyos pacientes tenían patología auditiva 0 vestibular debida a la ototoxicidad de los AAG. Estudio que estima que el 17\%-33\% de los pacientes con ototoxicidad por aminoglucósidos son portadores de la mutación A1555G2.

El estudio demuestra que la mutación genética determina una mayor susceptibilidad al efecto ototóxico a dosis bajas de estos antibióticos. La mutación A1555G en el gen del rRNA $12 S$ del genoma mitocondrial es responsable de hipoacusia no sindrómica, así como de un incremento en la susceptibilidad a la acción ototóxica de los aminoglucósidos. Parece que la mutación A1555G aumenta la similitud del rRNA 12S humano con su homólogo 16S bacteriano, produciendo un incremento en la unión del antibiótico ${ }^{13}$.

Esta mutación es transmitida por las madres a todos sus descendientes, tanto varones como mujeres $^{13}$.

Años atrás se planteó como teoría explicativa por medio de una acumulación selectiva de los AAG tanto a nivel de fluidos laberínticos como a nivel tisular, lo que actualmente se ha descartado.

\section{EVOLUCIÓN Y CLÍNICA}

La ototoxicidad se puede subdividir según distintos puntos de vista. Según la función comprometida 
en toxicidad coclear 0 auditiva y toxicidad vestibular. Según su evolución en el tiempo se hablará de aguda (reversible) e crónica (irreversible), teniendo como punto de corte 2-3 semanas posinterrupción del tratamiento ${ }^{14}$.

En el caso de la toxicidad coclear se han descrito dos estadios:

- Estadio inicial: el daño se limita a las frecuencias agudas $(4.000$ a $8.000 \mathrm{~Hz})$ y no afecta a las frecuencias utilizadas en una audición conversacional, aunque el paciente puede referir sensación de ruido y embotamiento auditivo. Los cambios tóxicos son generalmente reversibles en esta fase.

- Estadio avanzado: si la toxicidad continúa ya se afectan las CCI del apex coclear, y se afectan entonces las frecuencias más graves y la audición conversacional. En esta fase tardía el déficit suele ser permanente 0 sólo parcialmente reversible.

La toxicidad vestibular suele seguir un curso paralelo a la auditiva y se manifiesta por vértigo, náuseas, mareos y nistagmo, aunque es frecuente que quede encubierta por los mecanismos compensatorios visuales y propioceptivos.

La incidencia de pérdida de audición oscila entre $2 \%$ y $25 \%$. Este amplio rango puede ser debido en parte a la ausencia de una exploración auditiva sistematizada y a la ausencia de unos criterios uniformes para definir la ototoxicidad. Como la mayoría de los pacientes tratados con aminoglucósidos se pierden durante el seguimiento y los síntomas pueden ser inespecíficos, se desconoce si la ototoxicidad es permanente 0 transitoria.

\section{DIURÉTICOS DE ASA}

La ototoxicidad es una complicación que se veía mayormente con ácido etacrínico, actualmente en desuso, junto a otro diurético muy usado en la actualidad como es la furosemida. Ambos tienen en común el afectar el oído interno y al riñón. Desde el punto de vista histológico el daño se puede observar como:

- Edema intersticial

- Dislaceración de las células intermediarias y marginales

- Disminución de volumen de las células intermediarias

- Aumento de volumen de las células marginales

En general las lesiones histológicas se relacionan con efectos electrofisiológicos de los diuréticos sobre la estría vascular, que se resumen a nivel endolinfático en:

- Inhibición total del transporte activo durante repolarización

- Disminución de la permeabilidad de membra$\mathrm{na}$, principalmente a $\mathrm{K}^{+}$

\section{INTERACCIÓN ENTRE DIURÉTICOS DE ASA Y AAG}

Es conocido de mucho tiempo el gran riesgo ototóxico al administrar en forma simultánea un AAG y un diurético de asa. Estudios morfológicos han demostrado que la proporción de CCE destruidas por la kanamicina es mayor y por ende más importante, incluso con dosis más bajas de este AAG cuando se suma con un diurético.

El mecanismo de acción de los diuréticos es generar edema en el intersticio celular, lo que provoca un aumento de los espacios intercelulares de la estría vascular, que corresponde a la estructura coclear responsable de la etiogenia de los gradientes iónicos y la formación del potencial endococlear, esto facilita que los AAG poco ligados a las proteínas penetren y se propaguen lentamente a la endolinfa.

Tabla 2: Síntomas y signos de toxicidad coclear y vestibular

\begin{tabular}{|ll|}
\hline Coclear & Vestibular \\
\hline Acúfenos y/o Tinitus & Cefaleas \\
Pérdida alta frecuencia & Náuseas, vómitos, pérdida equilibrio en \\
Pérdida baja frecuencia (conversación) & deambulación (2 semanas) \\
La sordera puede aparecer varias semanas & Pérdida dequilibrio al cerrar párpados \\
después de interrumpir el tratamiento & Nistagmus \\
\hline
\end{tabular}


Ambos fármacos ejercen sus efectos ototóxicos de forma diferente, los diuréticos lo hacen a través de la estría vascular mientras que los AAG lo hacen en las estructuras sensoriales.

\section{CONCLUSIONES APLICADAS A LA PRÁCTICA CLÍNICA: FACTORES DE RIESGO}

Los factores de riesgo están divididos en los dependientes del médico y los dependientes del paciente.

\section{Factores dependientes del médico}

1. Duración del tratamiento, dosis cotidiana y dosis total: definidas para cada fármaco éstas deben ser rigurosamente respetadas. La captación histológica se caracteriza por su rapidez y saturabilidad. Por lo tanto dosis importantes facilitaran la aparición de fenómenos de toxicidad celular. Importante destacar que incluso respetando las dosis preestablecidas existe riesgo de ototoxicidad.

2. Modalidad de administración, dosis únicas 0 múltiples: La modalidad de administración del AAG representa un factor determinante. Se prefiere la vía intramuscular en monodosis, pues provoca picos menos bruscos que la vía endovenosa, que además, se recomienda administrar mediante perfusión durante 15-30 min. Los peak séricos cortos son menos tóxicos que las dosis bajas pero mantenidas, además que la acción bactericida es dosis dependiente y no tiempo dependiente. En cambio la forma ideal de administración de los diuréticos de asa es en dosis bajas y mantenidas en el tiempo, asociada a medición de niveles sanguíneos.

3. Tratamientos previos con AAG: La administración repetitiva de AAG conduce a un efecto acumulativo, esto explicado por su cinética de eliminación laberíntica extremadamente lenta.

4. Asociación AAG y diurético de asa: En lo posible debe ser evitada y si se realiza esta asociación tomar la prudencia correspondiente y supervisión de la función cocleovestibular.

5. Supervisión de la función cocleovestibular: El primer signo de toxicidad coclear es la afecta- ción de la percepción de sonidos de alta frecuencia, la cual no es perceptible ni por el propio sujeto ni por el examen clínico, por lo que la forma más precoz de detectar la alteración es la audiometría de alta frecuencia. Lo anterior tiene múltiples inconveniente: en primer lugar son escasos los audímetros de alta frecuencia $(8.000-20.000 \mathrm{~Hz})$ encontrándose mayormente difundidos los audímetros convencionales (250-8.000 Hz). En segundo lugar en nuestra realidad no se dispone de dicho examen en tal cantidad como se utilizan los AAG a diario. Por lo anterior, en la práctica diaria se debe tener presente la ototoxicidad medicamentosa y monitorizar clínicamente a todos nuestros pacientes, con una anamnésis y examen físico que sea lo más óptimo posible para un médico no especialista en otorrinolaringología (tanto un médico general como uno especialista de otra área), y a aquellos con mayor riesgo de ototoxicidad apoyar el monitoreo clínico con la audiometría.

Con respecto a la monitorización de la función vestibular se ha recomendado el estudio de la respuesta vestíbulo-oculares a los estímulos rotatorios sinusoidales calibrados y posturografia dinámica para detectar una lesión funcional, lo que es realmente impracticable en el diario vivir ${ }^{1}$.

Es importante destacar el gran retraso con que se diagnostica la ototoxicidad vestibular, el cual puede explicarse por varias razones.

a. La vestibulotoxicidad se desarrolla con retraso

b. Los síntomas aparecen en forma tardía porque generalmente los pacientes se encuentran en cama durante el tratamiento.

c. El médico ignora los síntomas de toxicidad vestibular y se deja engañar por la ausencia de síntomas de toxicidad coclear (síntomas auditivos)

d. El propio paciente ignora qué tratamientos a recibido

\section{Factores dependientes del paciente}

\section{Edad}

El niño está especialmente expuesto al riesgo de ototoxicidad. Existen múltiples dificultades en el diagnóstico precoz en el niño: 
- La patología que motivó la indicación del fármaco a menudo impide un análisis cocleovestibular inicial.

- La frecuente falta de cooperación en el niño hace difícil la realización de los test subjetivos

- Los test objetivos no siempre permiten detectar lesiones leves a moderadas

- Considerar además el mayor riesgo existente debido a las posologías más altas con respecto a los adultos y puede existir cierta predisposición genética a la ototoxicidad.

La gravedad de las afecciones cocleovestibulares en el niño no tan sólo implican prevenir una sordera sino también las consecuencias de ésta, por ejemplo, una rápida degradación del lenguaje, en una etapa de la vida que éste se encuentra en desarrollo.

También presentan mayor riesgo los pacientes ancianos por múltiples razones:

- El deterioro progresivo de la función laberíntica propio de la edad, el cual predispone consecuencias más severas

- Los cambios farmacocinéticos que ocurren como deterioro de la función renal y disminución del agua constitucional con aumento de la proporción grasa, determina un mayor riesgo de toxicidad.

- Las morbilidades y los tratamientos que la persona a recibidos durante toda una vida

- En el caso de una toxicidad vestibular su impacto será mayor que en un paciente joven. Lo anterior debido a que la compensación visual y propioceptiva esperada para mantener el equilibrio será deficiente pues estos sistemas también están deteriorados por la edad y las comorbilidades.

\section{Insuficiencia renal}

Los AAG son exclusivamente eliminados por filtración glomerular, por consiguiente una falla renal determinaría un aumento en las concentraciones plasmáticas, aumentando el riesgo de ototoxicidad. En la practica el medico antes de iniciar un tratamiento con AAG o diuréticos debería constatar el estado de la función renal y mantener un monitoreo periódico. En esta situación se debe aclarar que no existe ni dosis ni niveles plasmáticos seguros que brinden protección absoluta.
Pacientes con mayor riesgo de ototoxicidad

A. Pacientes niños y ancianos

B. Pacientes con insuficiencia renal

C. Paciente con tratamientos prolongados $y / 0$ en altas dosis

D. Pacientes con daño previo en su oído interno

E. Pacientes con antecedentes de haber recibido ototóxicos previos

F. Pacientes cuya profesión requiere un equilibrio fino (bailarinas y pilotos) ${ }^{1,14}$.

\section{OTOTOXIDAD LOCAL}

Existe un uso excesivo de gotas óticas que combinan antibióticos, antiinflamatorios, antisépticos y disolventes, costumbre común entre los médicos de múltiples países, para el tratamiento de las perforaciones con otorrea y de las otorreas a través de un tubo de aireación transtimpánico. El argumento para esta conducta es que es más importante el riesgo de hipoacusia sensorioneural debidas a la otitis media que el provocado por el uso de gotas óticas.

Está demostrada la ototoxicidad de los aminoglucósidos de uso tópico, sin embargo, para que esto ocurra deben alcanzar los neuroreceptores ubicados en el oído interno, lo que en la práctica no sucede debido a que:

1. Para alcanzar el oído interno, las gotas óticas instiladas en el conducto auditivo externo, deben alcanzar inicialmente el oído medio, lo que no ocurre cuando la membrana timpánica no presenta alguna solución de continuidad. En el caso de existir tal, la inflamación de la mucosa a menudo constituye un impedimento para la difusión del producto.

2. Una otorrea, purulenta 0 no, muestra un gradiente de presión positiva del oído medio hacia el oído externo que se opone a la penetración de las gotas

3. Existe importantes diferencias anatómicas entre el oído medio del animal y del hombre. En este último la ventana redonda está protegida del paso de las gotas óticas por un importante borde óseo.

4. La técnica de instilación a menudo es incorrecta.

Pese a lo anterior, en Reino Unido, la Agencia Reguladora de Medicamentos y Productos Sanita- 
rios (Medicines and Healthcare Products Regulatory Agency-MHRA) (CSM 1997) no recomienda su uso en pacientes con una perforación de la membrana timpánica ${ }^{15}$.

Por otra parte los efectos ototóxicos locales de los aminoglucósidos se aprovechan en el tratamiento de ciertos casos de enfermedad de Méniere unilateral, para eliminar las crisis de vértigo.

\section{FÁRMACOS ANTINEOPLÁSICOS}

Se trata esencialmente de sustancias que pertenecen a la familia del cisplatino, aunque otras drogas como la vincristina, también puede ejercer cierta acción ototóxica. Los principales síntomas que presentan los pacientes son acúfenos, anacusia y otalgia, destacando que este último síntoma no está presente en clínica de ototoxicidad producida por otros fármacos. En el caso de la hipoacusia esta se presenta en las frecuencias agudas y es bilateral'.

\section{COMENTARIOS}

Cada día aumenta en forma considerable el uso de fármacos antibióticos y con ello también aumentan las posibilidades de que ocurran reacciones adversas a estos fármacos como lo es la ototoxicidad. Lo anterior hace imprescindible la constante actualización del clínico en estos temas, que son comunes para múltiples especialidades médicas, y así evitar cometer iatrogenia.

\section{BIBLIOGRAFÍA}

1. Dauman $R$ et Dulon D. Ototoxicité médicamenteuse. Encycl Méd Chir (Editions Scientifiques et Médicales Elsevier SAS, Paris), Oto-rhino laryngologie, 20-184-B-10, 1995, 10p.

2. Palomar García $V$, Abdulghani F, Bodet E, Andreu Mencía L, Palomar Asenjo V. Otoxicidad producida por medicamentos: Estado actual, ORLDIPS 2001; 28 (1):7-11.
3. Palomino Julián y Pachón Jerónimo. Enfermedades Infecciosas. Microbiología Clínica 2003; 21(2): 105-15.

4. WALKSMAN SA. Streptomycin: background, insolation, properties and utilization. Science 1953; 118: 259-66.

5. HawkINS JE. Ototoxicity. In: Maran AGD, Stell PD eds. Clinical Otorrilaringology. Blackwell Scientific. 1979: 92-9.

6. Sснаснт J. Biochemical basis of aminoglycoside ototoxicity. Otol Clin Nort Am 1993; 26: 845-56.

7. Bonnie W, Ramsey. Management of Pulmonary Disease in Patients with Cystic Fibrosis. N Engl J Med 1996; 335: 179-87.

8. Lacy MK, Nicolau DP, Nightingale CH, Quintiliani $\mathrm{R}$. The pharmacodynamics of aminoglycosides. Clin Infect Dis 1998; 27: 23-7.

9. Van De Graaf, Kent, Stuart Ira Fox. Senses of Hearing and Balance, Concepts of Human Anatomy and Physiology, WM. C Brown Publishers 2ª edition, 1996.

10. Gerónimo Pardo M, Mateos Rodríguez F, Blanch Sancho JJ, Martínez Alfaro E. Antibióticos Aminoglucósidos. Medicine 2002; 8(65): 3470-9.

11. Patrick J. Willems. Genetic Causes Of Hearing Loss. N Engl J Med 2000; 342: 1101-9.

12. Morton Cynthia C., Ph.D., and Nance Walter E., M.D., Pн.D. Newborn Hearing Screening A Silent Revolution. N Engl J Med. 2006; 354: 2151-64.

13. Gallo-Terán J, Arellano B, Morales-Angulo $C$ et AL. Prevalencia de la Mutación A1555g en el ADN Mitocondrial en Pacientes con Patología Auditiva o Vestibular Debida a la Ototoxicidad De Los Aminoglucósidos. Acta Otorrinolaringología Española 2004; 55: 212-7.

14. Brummett Re, Fox Ke. Studies of aminoglycoside ototoxicity in animal models. In: Whelton A Neu HC eds The Aminoglycosides: Microbiology. Clinical Use And Toxicology, Mercel Dekker, New York, 1982; 419-51.

15. Macfadyen CA, Acuin JM, Gamble C. Antibióticos tópicos sin esteroides para la secreción ótica crónica con perforación de tímpano subyacente (Revisión Cochrane traducida). En: La Biblioteca Cochrane Plus, 2006 Número 2. 